\title{
Article \\ An Analytical Model for the Uniaxial Tensile Modulus of Plain-Woven Fabric Composites and Its Application and Experimental Validation
}

\author{
Rui Zhou, Weicheng Gao *(D), Wei Liu and Jianxun Xu \\ Department of Astronautics Science and Mechanics, Harbin Institute of Technology, Harbin 150001, China; \\ zhourui3805@buaa.edu.cn (R.Z.); weiliu@hit.edu.cn (W.L.); 21b918006@stu.hit.edu.cn (J.X.) \\ * Correspondence: gaoweicheng@sina.com
}

Citation: Zhou, R.; Gao, W.; Liu, W.; $\mathrm{Xu}, \mathrm{J}$. An Analytical Model for the Uniaxial Tensile Modulus of PlainWoven Fabric Composites and Its Application and Experimental Validation. Aerospace 2022, 9, 26. https: / / doi.org/10.3390/ aerospace 9010026

Academic Editor: Doni Daniel

Received: 3 December 2021

Accepted: 30 December 2021

Published: 4 January 2022

Publisher's Note: MDPI stays neutral with regard to jurisdictional claims in published maps and institutional affiliations.

Copyright: (c) 2022 by the authors. Licensee MDPI, Basel, Switzerland. This article is an open access article distributed under the terms and conditions of the Creative Commons Attribution (CC BY) license (https:/ / creativecommons.org/licenses/by/ $4.0 /)$.

\begin{abstract}
With advantages in efficiency and convenience, analytical models using experimental inputs to predict the mechanical properties of plain-woven fabric (PWF) composites are reliable in guaranteeing the composites' engineering applications. Considering the importance of the aspect above, a new analytical model for predicting the uniaxial tensile modulus of PWF is proposed in this article. The composite yarns are first simplified as the lenticular-shaped cross-sections undulate along arc-composed paths. Force analyses of the yarn segments are then carried out with the internal interactions simplified, and the analytical model is subsequently deduced from the principle of minimum potential energy and Castigliano's second theorem. The PWF of T300/Cycom970 is chosen as the study object to which the proposed analytical model is applied. Microscopic observations and thermal ablation experiments are conducted on the specimens to obtain the necessary inputs. The uniaxial tensile modulus is calculated and tensile experiments on the laminates are performed to validate the analytical prediction. The small deviation between the experimental and analytical results indicates the feasibility of the proposed analytical model, which has good prospects in validating the effectiveness of the experimentally obtained modeling parameters and guaranteeing the accuracy of mesoscale modeling for the PWF.
\end{abstract}

Keywords: analytical model; energy method; textile composites; elastic properties; experimental validation

\section{Introduction}

With the characteristics of lighter weight in addition to higher stiffness and strength, fiber-reinforced composites have been widely used in the aerospace industry. In order to reduce production costs and simplify the machining processes plain-woven fabric composites are becoming increasingly important in the design and manufacturing of lightweight aerospace structures.

With the aim of improving the level of structural design and analysis, it is necessary to understand the loading response and failure mechanism of plain-woven composites. Research has been widely carried out and various experimental techniques as well as methods have been utilized in the study of plain-woven composites. X-ray tomography and microscale measurement systems are important in measuring the 3D coordinates of plain-woven composites' mesoscale structures and establishing mesoscale geometric models. Experimental observations based on the above methods [1,2] have contributed to a direct understanding of the composites' woven morphology and offered enlightenment in the accurate modeling of the interlaced yarns. Wang et al. [3] used micro-CT equipment with a high-resolution lens-coupled detector to reconstruct 3D images of $\mathrm{C}$ /epoxy plainwoven composites. Based on the obtained clear 3D image of the T300/epoxy material, the statistical properties of the yarn feature parameters that were then analyzed. Scanning electron microscopes (SEMs) and digital imaging systems are also frequently used in the 
microscopic observations of composites. With the assistance of microscopic observations, Carvalho et al. [4] investigated the compressive failure of orthogonal 2D woven composites. The regional failure of the load-aligned tows was studied and the damage propagation process was analyzed in detail. Specialized fixtures have also been designed for different test targets. With a picture-frame apparatus Nguyen et al. [5] studied the shearing properties of plain-woven fabrics and prepregs. Experimental investigations on the shear properties of the fabric composites were conducted and the relationships between the shearing angle and the applied load for different weave architectures were analyzed.

Experimental results provide the basis on which plain-woven composites could be modeled. With the numerical models, the finite-element (FE) method has been widely applied in the analysis of plain-woven fabrics due to its advantages in calculation efficiency and low cost. In the FE modeling of plain-woven fabrics the industrial application of advanced meshing methods has attracted a growing interest due to its operational convenience [6]. The applicability of voxel meshes in the numerical modeling of plainwoven composites was studied by Doitrand et al. [7], and the calculation accuracy of the voxel method was evaluated. Grail et al. [8] developed an automated method to generate consistent FE meshes for plain-woven composites. Based on the proposed method, a representative unit cell (RUC) of a compacted and nested multilayer woven composite was generated.

Obtaining the mechanical properties of the plain-woven composites and evaluating the properties' effects are necessary preconditions for the following structural analysis. With the assistance of RUC models and FE analyses, Goyal et al. [9] investigated the effects of geometric parameters and basic material properties on the effective engineering properties of plain-woven braids. Matveev et al. [10] numerically studied the effects of fiber strength on the macroscale strength of textile composites and found that a wide fiber strength distribution led to a narrow distribution of composite strength. In evaluating the mechanical properties' effects and predicting the mechanical response of braided composites, Richter et al. [11] proposed a simulation framework with a meshing methodology that considered yarn-to-yarn delamination. The validation of the framework underlined the great potential for further damage modeling of the fabric composites.

The simulation of failure is also an important concern in the FE analysis of fabrics. In order to understand the elementary damage mechanisms and investigate the development of damage in detail, advanced techniques such as improved two-dimensional generalized plane strain FE models [12], the cracking kinetics simulation [13] and shear nonlinearity incorporated failure process modeling [14] have been utilized in investigations. Important damage details have been captured and the relationships between ply damage behaviors and elementary damage mechanisms have been linked.

Macro fabric composite structures could be further studied at the mesoscale of the fiber tows and the microscale of the constituents. In the multiscale failure analyses of the fabric composites micromechanics-based failure theories [15-18] are becoming increasingly appealing for researchers due to their advantage in explaining the failure of composites at the constituent level [19]. By combining macroscale FE models with RUCs of meso- and microscales the multiscale analysis method takes the advantages of both the efficiency of the macro analysis and the accuracy of the micromechanics-based failure criteria [20]. The effectiveness of the multiscale analysis in predicting the fabric composites' damage initiation and failure process [21-23] indicated the huge potential of the micromechanicsbased methods' further engineering applications.

The mesoscale RUC is an important stress transformation medium of the plain-woven fabric composites' multiscale analysis, and its accurate establishment is necessary for further failure analysis. Microscopic observations and basic tests could be conducted, making it convenient to obtain the geometric and mechanical parameters of the fabric composites. However, the feasibility of the experimentally obtained parameters in modeling the RUC needs further validation considering the dispersibility and errors in the experiments. In predicting the properties of textile composites, analytical solutions suitable for engineering 
applications have been proposed [24-28]. Although the theoretical foundations are solid the geometric parameters and internal force analyses have been oversimplified and idealized in previous research [24,28], and the prediction accuracy could be further raised with the improvement of the previous models. Using the fiber tows' geometric and mechanical parameters as inputs and having an advantage in calculation efficiency, reliable analytical models have broad prospects in engineering applications in validating the effectiveness of the experimentally obtained modeling parameters and guaranteeing the accuracy of the established RUC.

In this article attempts have been made to develop a new reliable analytical model with experimental inputs in calculating the uniaxial tensile modulus of plain-woven fabric composites.

In the Section 2 the cross-section and undulation path of the fiber tows are reasonably simplified and geometrically expressed with parameters and formulations. Within the mesoscale RUC the studied yarn segments are assigned.

In the Section 3 the interactions between the warp and weft yarns are simplified and the internal forces of the studied yarn segments are analyzed in detail.

In the Section 4 the analytical model is developed. The analytical solution for the uniaxial tensile modulus is derived from the elastic deformation energy analysis with the fiber tows' internal forces more comprehensively considered. The necessary parameters of inputs are referred and the matched experiments to obtain the parameters are designed.

Finally, in the Section 5 the proposed analytical model is applied to predict the uniaxial tensile modulus of T300/Cycom970, and the application process is introduced in detail. Tensile experiments on the T300/Cycom970 laminates are conducted and the effectiveness of the analytical model is validated.

\section{Simplification of the Cross-Section and Undulation Path of the Fiber Tows}

Due to the randomness of the woven prepregs and the influence of the hot-pressing manufacturing process there are difficulties in accurately describing the irregular-shaped cross-section of the fiber tows with certain parameters. Therefore, the simplification of the cross-section is needed as an important basis for the analytical solution of the fabric composites. Compared to the observations from computed tomography (CT), as illustrated in Figure 1a, previous research results $[29,30]$ indicate that the lenticular shape best approaches the cross-section of the plain-woven composites' fiber tows. Besides, the lenticular-shaped cross-section exceeds the other frequently used sections in ensuring the fiber tows of the warp and weft directions realistically contact without interpenetration. Considering the above advantages, the lenticular shape is chosen to simplify the cross-section of the fiber tows in this article.

The warp yarn is taken as the example and the cross-section is projected onto the $\mathrm{Y}-\mathrm{Z}$ plane, as presented in Figure $1 \mathrm{~b}$. The controlling parameters in defining the lenticularshaped cross-section are $a, b$ and $r_{T}$, which represent the width, thickness and controlling radius of the cross-section, respectively:

$$
r_{T}-\sqrt{r_{T}^{2}-\frac{1}{4} a^{2}}=\frac{1}{2} b
$$

In Figure $1 b, z$ stands for the ordinate value of the $Y-Z$ plane and $L(z)$ stands for the $z$-corresponded horizontal intercept of the cross-section. The area, $A$, and the inertia moment of the cross-section, $I$, for the fiber tows in the warp and the weft directions are then expressed as follows:

$$
\begin{gathered}
A=\int_{A} d A=2 \int_{0}^{b / 2} L(z) d z \\
I=I_{x}=I_{y}=\int_{A} z^{2} d A=2 \int_{0}^{b / 2} z^{2} L(z) d z
\end{gathered}
$$


(a)

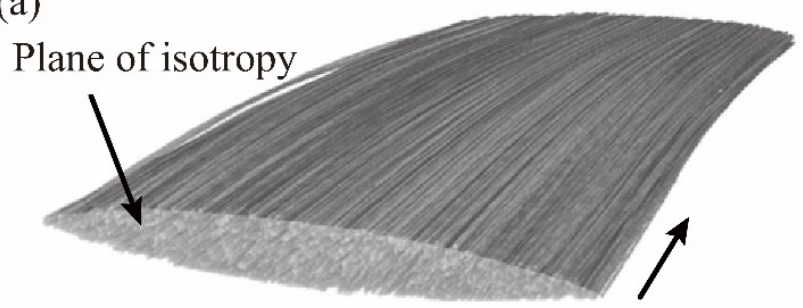

(b)

\section{Direction of fibers}
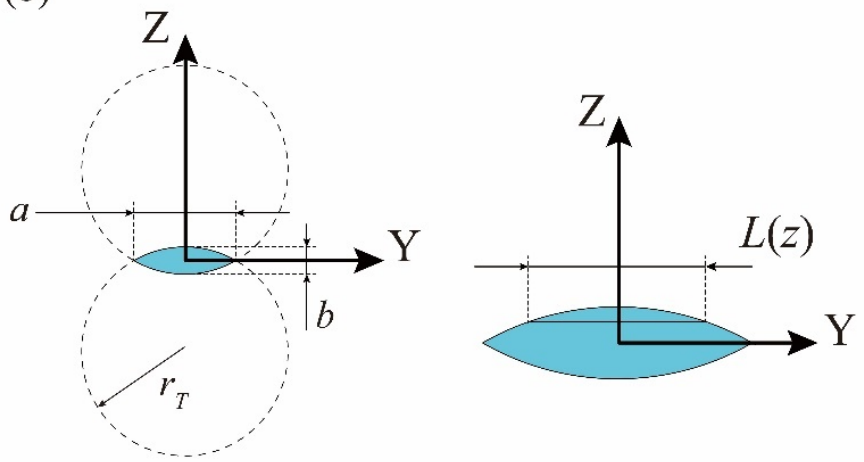

Figure 1. The lenticular-shaped cross-section of the fiber tows and the corresponding geometric parameters: (a) experimental CT image of the fiber tow [29]; (b) geometric parameters of the lenticularshaped cross-section.

Referring to Equation (1), the area and the inertia moment are further expressed as:

$$
\begin{aligned}
& A=4 \int_{0}^{b / 2} \sqrt{\left(\frac{a^{2}+b^{2}}{4 b}\right)^{2}-\left[\sqrt{\left(\frac{a^{2}+b^{2}}{4 b}\right)^{2}-\left(\frac{1}{2} a\right)^{2}}+z\right]} d z \\
& I=4 \int_{0}^{b / 2} z^{2} \sqrt{\left(\frac{a^{2}+b^{2}}{4 b}\right)^{2}-\left[\sqrt{\left(\frac{a^{2}+b^{2}}{4 b}\right)^{2}-\left(\frac{1}{2} a\right)^{2}}+z\right] d z}
\end{aligned}
$$

Corresponding to the lenticular-shaped cross-section, the undulation path composed of arcs with the same radius is used in this article. With the periodic characteristics of the plain-woven fabric composites, the analysis is performed on the mesoscale RUC, inside of which the segments of the warp and weft yarns are taken as the study objects, as illustrated in Figure 2.
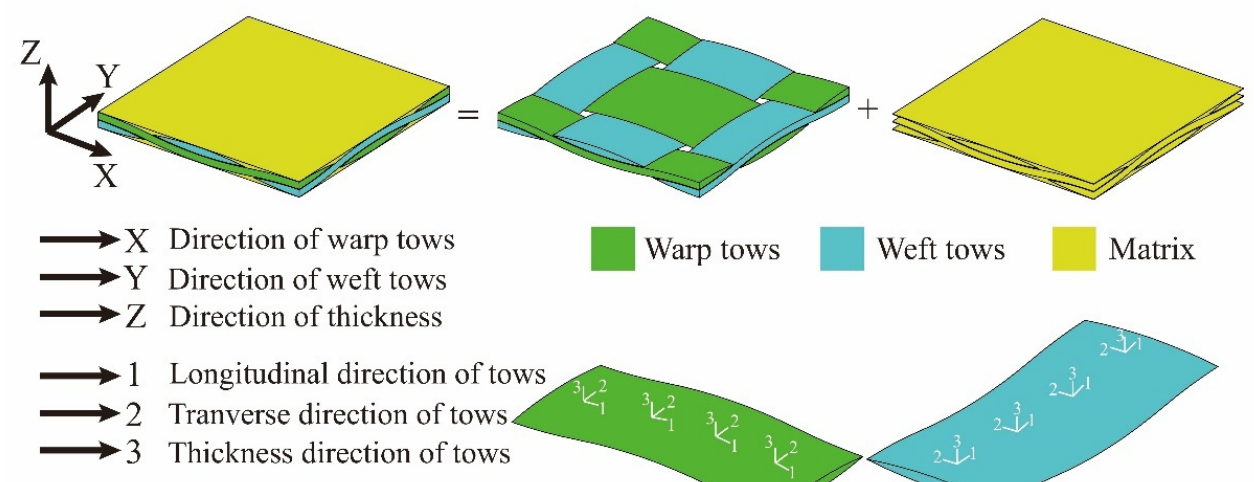

X Direction of warp tows

Yirection of weft tows

Warp tows

Weft tows

Matrix

Direction of thickness

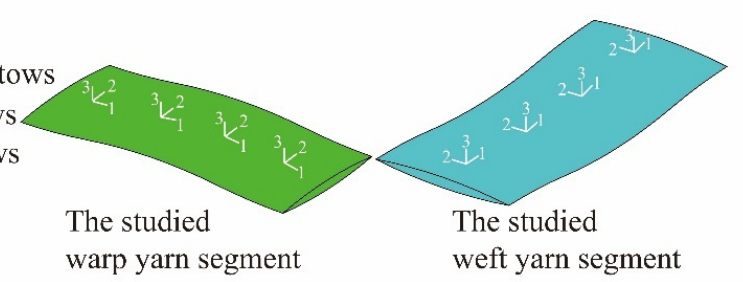

Figure 2. RUC of the plain-woven fabric composites and the studied warp and weft yarn segments. 
The undulation path of the studied warp yarn segment is presented in Figure $3 a . r_{U}$ represents the radius of the arcs and $L_{R U C}$ represents the length of the mesoscale RUC. $H$ stands for the distance between the horizontal center line of the RUC and the center of the arcs in the undulation path:

$$
H=\sqrt{r_{U^{2}-\left(\frac{1}{4} L_{R U C}\right)^{2}}}
$$

(a)

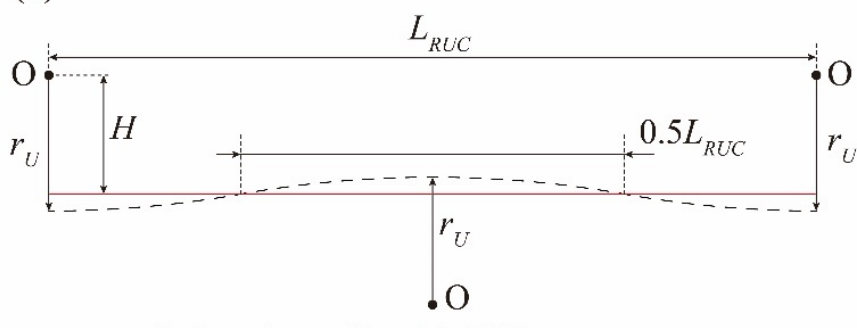

Horizontal center line of the RUC



(b)



Figure 3. The undulation paths of the studied yarn segments: (a) the undulation path of the warp yarn segment; (b) the undulation path of the weft yarn segment.

For the studied weft yarn segment in Figure 2 the geometric parameters of the undulation path in Figure $3 b$ remain the same, and the width of the mesoscale RUC $\left(W_{R U C}\right)$ is equal to $L_{R U C}$, considering the plain-woven structure of the fabric composites.

In the $x$ range of $\left(0, \frac{1}{2} L_{R U C}\right)$ the undulation path function $z_{1}(x)$ of the warp yarn segment corresponding to Figure $3 a$ is expressed as:

$$
z_{1}(x)=\left\{\begin{array}{c}
r_{U}-\sqrt{r_{U^{2}}-x^{2}}, x=0 \\
\sim \frac{1}{4} L_{R U C} \\
r_{U}-2 H+\sqrt{r_{U^{2}}-\left(x-\frac{1}{2} L_{R U C}\right)^{2}}, x=\frac{1}{4} L_{R U C} \sim \frac{1}{2} L_{R U C}
\end{array}\right.
$$

Similarly, for the weft yarn segment in Figure $3 b$ the undulation path function $z_{2}(y)$ is expressed as:

$$
z_{2}(y)=\left\{\begin{array}{c}
r_{U}-2 H+\sqrt{r_{U}^{2}-y^{2}}, y=0 \sim \frac{1}{4} W_{R U C} \\
r_{U}-\sqrt{r_{U^{2}}-\left(y-\frac{1}{2} W_{R U C}\right)^{2}}, y=\frac{1}{4} W_{R U C} \sim \frac{1}{2} W_{R U C}
\end{array}\right.
$$




\section{Force Analysis of the Fiber Tows under Uniaxial Tension Load}

The monolayer of the plain-woven fabric composites under the uniaxial tension load along the warp direction is presented in Figure 4a. As the warp yarns are straightened the distributed interaction force of $q$ between the weft and warp yarns exists in hindering the straightening of the warp yarns and causing the crimping of the weft yarns. For the convenience of the following analyses the distributed interaction force of $q$ is simplified as the concentrate force of $Q$, as illustrated in Figure $4 \mathrm{~b}$.

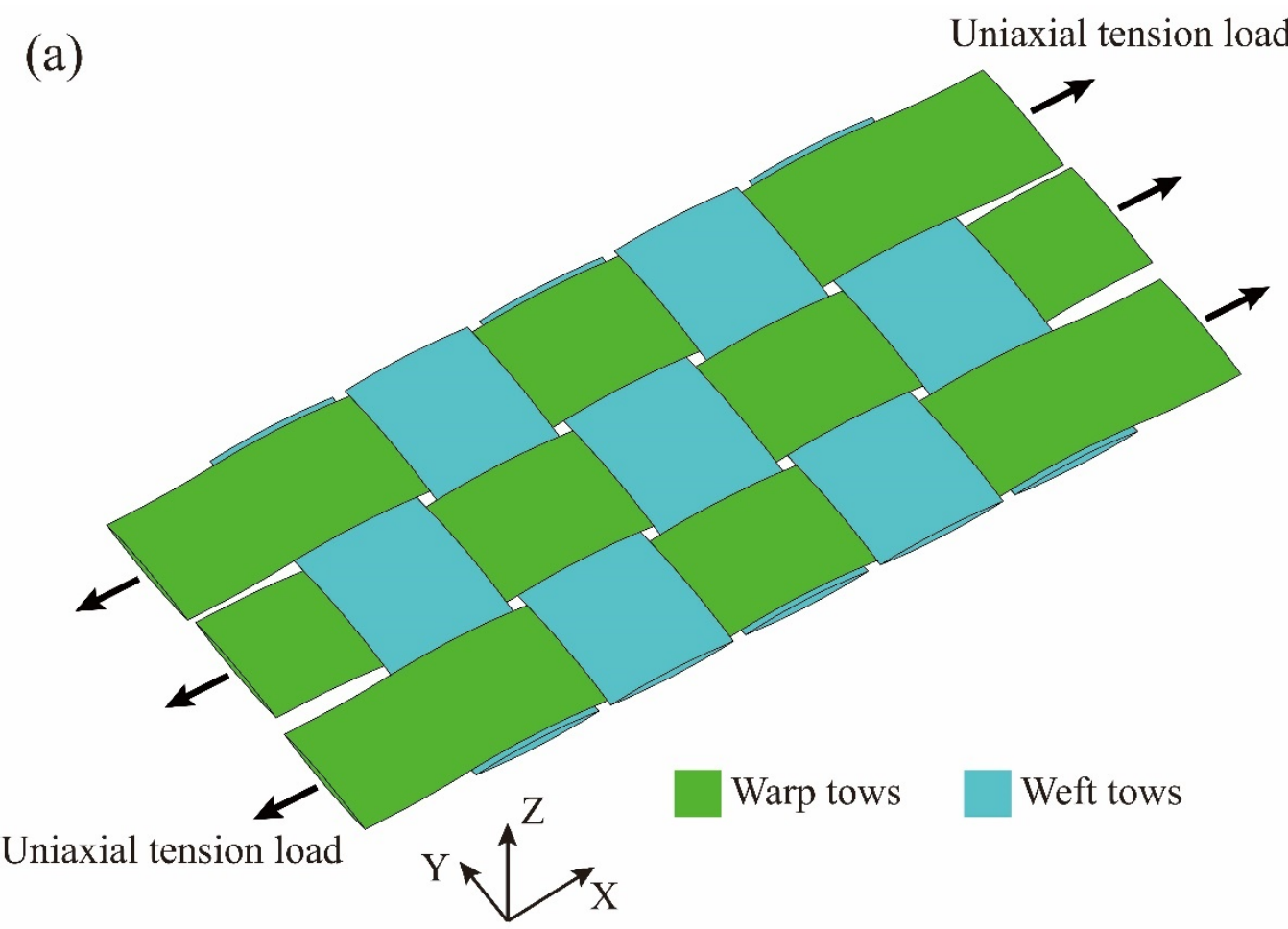

(b)

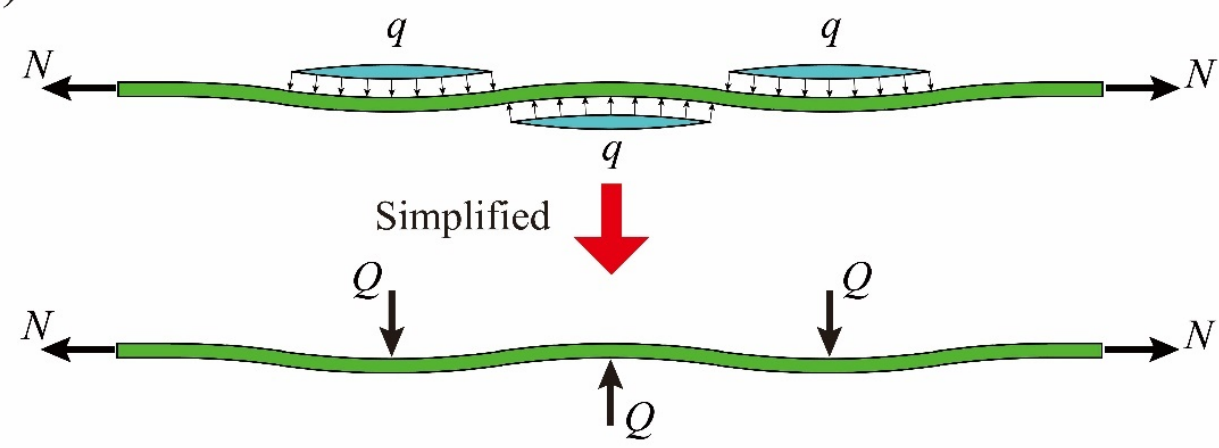

Figure 4. Interactions between the fiber tows: (a) the monolayer of the plain-woven fabric composites under uniaxial tension load; (b) simplification of the interactions between the warp and weft tows.

For the studied mesoscale RUC of the plain-woven fabric composites in Figure 2, the force analyses of the warp and weft yarn segments are illustrated in Figure 5. 
(a)
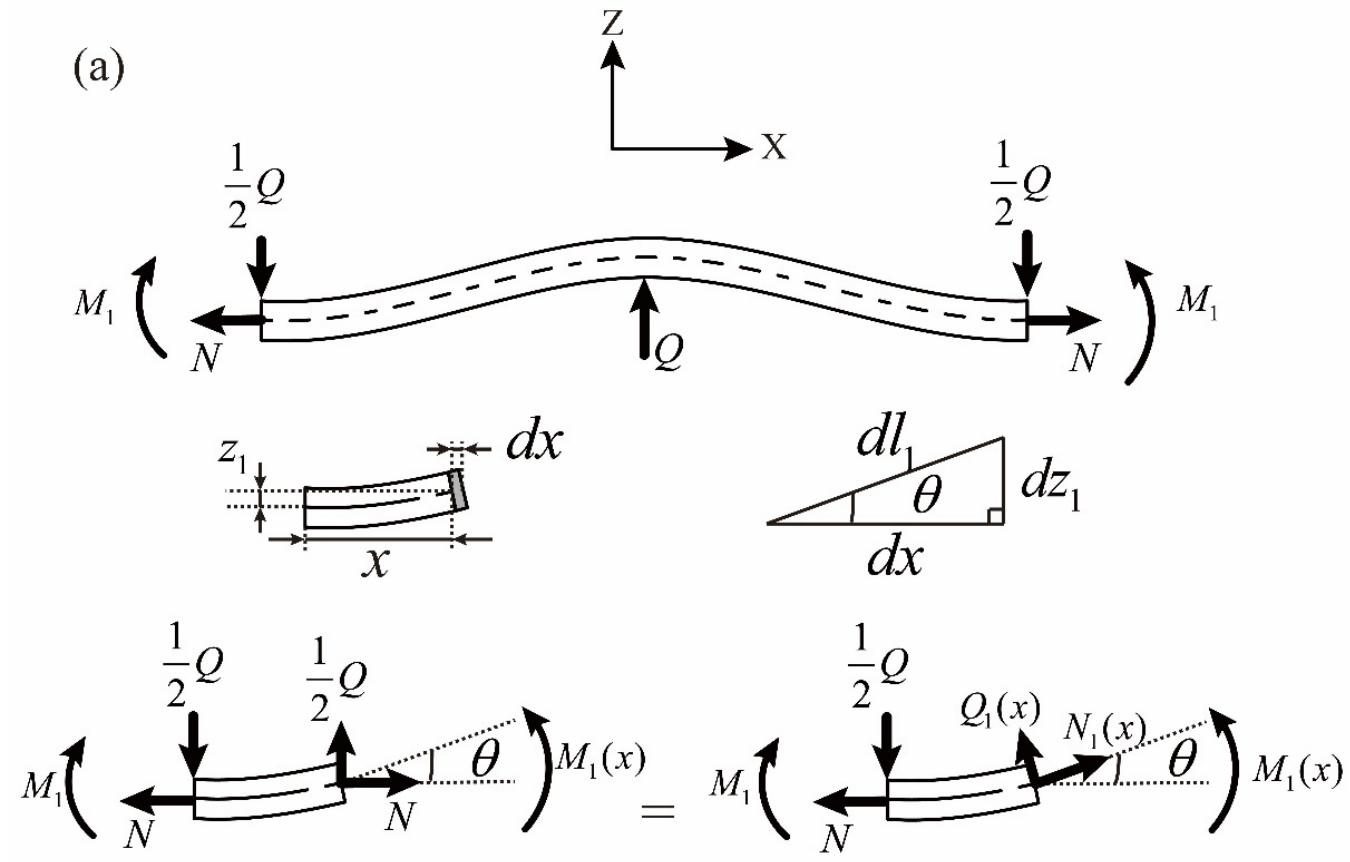

(b)
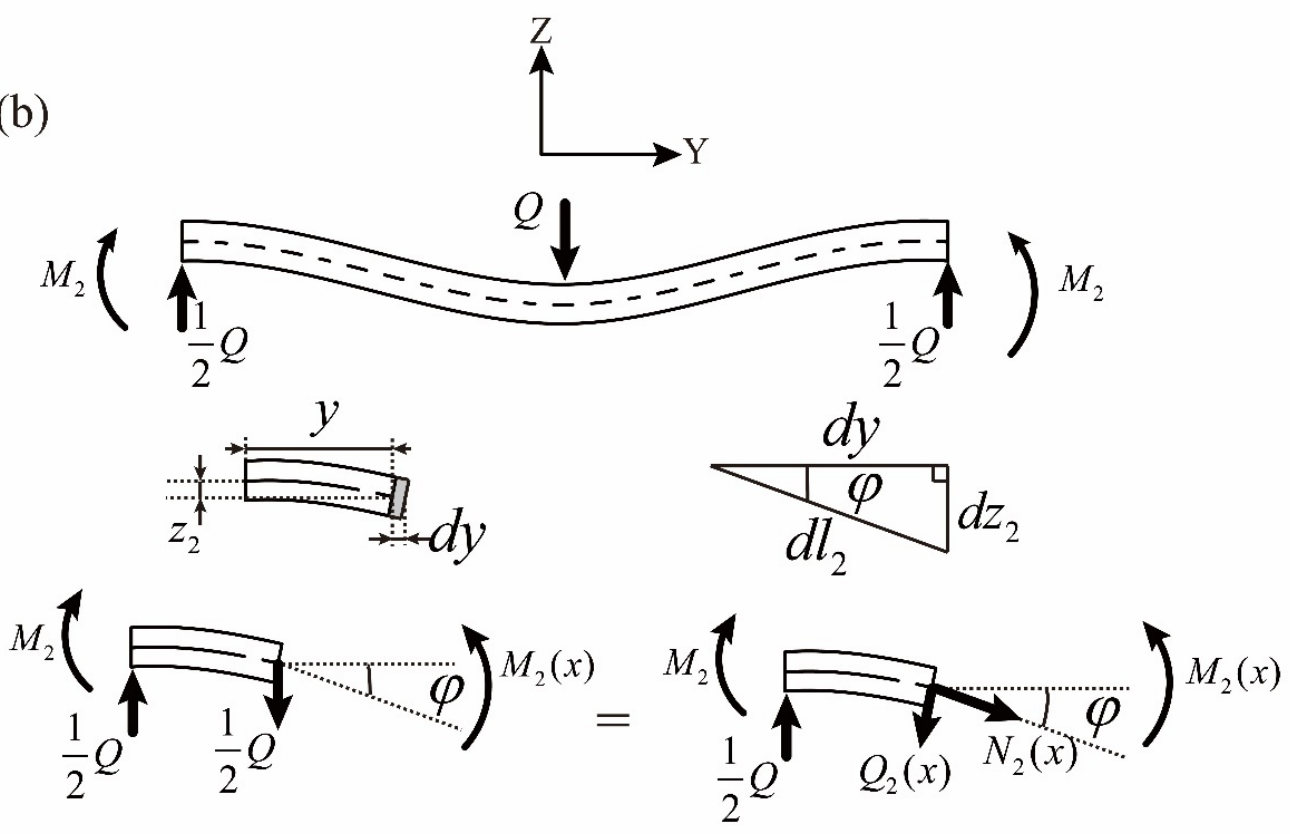

Figure 5. Force analyses of the studied yarn segments: (a) force analysis of the warp yarn segment; (b) force analysis of the weft yarn segment.

In Figure 5a the axial load of $N$ and the constraint moment of $M_{1}$ are loaded at the boundary cross-sections of the warp yarn segment. The interaction loads of $Q$ and $\frac{1}{2} Q$ from the weft yarns concentrate at the middle location and the left and right endpoints, respectively. $d l_{1}$ stands for the differential length of the warp yarn segment and $\theta$ stands for the angle between $d l_{1}$ and the $\mathrm{X}$-axis. At the $x$-corresponded cross-section in the warp yarn segment the horizontal internal load of $N$ and the vertical internal load of $\frac{1}{2} Q$, which satisfy the force balance condition, are further converted into the internal tensile load $N_{1}(x)$ and the internal shearing load $Q_{1}(x)$, which are perpendicular and parallel to the cross-section, respectively. 
For the cross-sections of the studied warp yarn segment, within the range of $\left(0, \frac{1}{2} L_{R U C}\right)$ along the $\mathrm{X}$-axis, the internal bending moment $M_{1}(x)$ is expressed as:

$$
M_{1}(x)=M_{1}+N z_{1}(x)-\frac{1}{2} Q x
$$

The internal tensile load $N_{1}(x)$ is expressed as:

$$
N_{1}(x)=N \cos \theta+\frac{1}{2} Q \sin \theta=\frac{N}{\sqrt{1+\tan ^{2} \theta}}+\frac{Q \tan \theta}{2 \sqrt{1+\tan ^{2} \theta}}
$$

Additionally, the internal shearing load $Q_{1}(x)$ is expressed as:

$$
Q_{1}(x)=N \sin \theta-\frac{1}{2} Q \cos \theta=\frac{N \tan \theta}{\sqrt{1+\tan ^{2} \theta}}-\frac{Q}{2 \sqrt{1+\tan ^{2} \theta}}
$$

For the weft yarn segment in Figure $5 b$ the constraint moments of $M_{2}$ are loaded at the boundary cross-sections and the interaction loads of $Q$ and $\frac{1}{2} Q$ from the warp yarns concentrate at the middle location and the left and right endpoints, respectively. The angle between the differential length of the weft yarn segment $d l_{2}$ and the Y-axis is presented as $\varphi$. Similar to the warp yarn segment, the vertical internal load of $\frac{1}{2} Q$ at the $y$-corresponded cross-section in the weft yarn segment is converted into the internal tensile load $N_{2}(y)$ and the internal shearing load $Q_{2}(y)$.

For the cross-sections of the studied weft yarn segment, within the range of $\left(0, \frac{1}{2} W_{R U C}\right)$ along the Y-axis, the internal bending moment $M_{2}(y)$ is expressed as:

$$
M_{2}(y)=M_{2}+\frac{1}{2} Q y
$$

The internal tensile load $N_{2}(y)$ is expressed as:

$$
N_{2}(y)=\frac{1}{2} Q \sin \varphi=\frac{Q \tan \varphi}{2 \sqrt{1+\tan ^{2} \varphi}}
$$

Additionally, the internal shearing load $Q_{2}(y)$ is expressed as:

$$
Q_{2}(y)=\frac{1}{2} Q \cdot \cos \varphi=\frac{Q}{2 \sqrt{1+\tan ^{2} \varphi}}
$$

Considering the arc-shaped undulation paths of the warp and weft yarns, the tangents of $\theta$ and $\varphi$ are, respectively, expressed as:

$$
\begin{gathered}
\tan \theta=\frac{d z_{1}}{d x}=\left\{\begin{array}{c}
\frac{x}{\sqrt{r_{U}^{2}-x^{2}}}, x=0 \sim \frac{1}{4} L_{R U C} \\
\frac{\frac{1}{2} L_{R U C}-x}{\sqrt{r_{U^{2}}-\left(x-\frac{1}{2} L_{R U C}\right)^{2}}}, x=\frac{1}{4} L_{R U C} \sim \frac{1}{2} L_{R U C}
\end{array}\right. \\
\tan \varphi=\frac{d z_{2}}{d y}=\left\{\begin{array}{c}
\frac{-y}{\sqrt{r_{U}^{2}-y^{2}}}, y=0 \sim \frac{1}{4} W_{R U C} \\
\frac{y-\frac{1}{2} W_{R U C}}{\sqrt{r_{U} U^{2}-\left(y-\frac{1}{2} W_{R U C}\right)^{2}}}, y=\frac{1}{4} W_{R U C} \sim \frac{1}{2} W_{R U C}
\end{array}\right.
\end{gathered}
$$

\section{Analytical Solution in Predicting the Uniaxial Tensile Modulus of the Plain-Woven Fabric Composites}

The parameters of $E_{11(t o w)}, G_{12 \text { (tow) }}$ and $G_{13 \text { (tow) }}$ stand for the longitudinal modulus, the in-plane shear modulus and the out-of-plane shear modulus of the plain-woven fabric composites' fiber tows, respectively. Under the hypothesis of transverse isotropy $G_{12(t o w)}$ is equal to $G_{13(t o w)}$. $L_{1}$ and $L_{2}$ stand for the lengths of the warp and weft yarn segments 
illustrated in Figure 2, respectively. Under the hypothesis that the shearing stress is uniformly distributed on the fiber tow's cross-section the strain energy of the studied warp yarn segment is presented as $U_{1}$ :

$$
\begin{aligned}
& U_{1}=\frac{1}{2 E_{11 \text { (tow })} I} \int_{0}^{L_{1}} M_{1}(x)^{2} d l_{1}+\frac{1}{2 E_{11(\text { tow })} A} \int_{0}^{L_{1}} N_{1}(x)^{2} d l_{1}+\frac{1}{2 G_{13(\text { tow })} A} \int_{0}^{L_{1}} Q_{1}(x)^{2} d l_{1} \\
& =\frac{1}{2 E_{11(\text { tow })} I} \int_{0}^{L_{R U C}} \frac{M_{1}(x)^{2}}{\cos \theta} d x+\frac{1}{2 E_{11(\text { tow })} A} \int_{0}^{L_{R U C}} \frac{N_{1}(x)^{2}}{\cos \theta} d x+\frac{1}{2 G_{13(\text { tow })} A} \int_{0}^{L_{R U C}} \frac{Q_{1}(x)^{2}}{\cos \theta} d x
\end{aligned}
$$

For the studied weft yarn segment the strain energy $U_{2}$ is expressed as:

$$
\begin{aligned}
& U_{2}=\frac{1}{2 E_{11(\text { tow })} I} \int_{0}^{L_{2}} M_{2}(y)^{2} d l_{2}+\frac{1}{2 E_{11(\text { tow })} A} \int_{0}^{L_{2}} N_{2}(y)^{2} d l_{2}+\frac{1}{2 G_{13(\text { tow })} A} \int_{0}^{L_{2}} Q_{2}(y)^{2} d l_{2} \\
& =\frac{1}{2 E_{11 \text { (tow })} I} \int_{0}^{W_{R U C}} \frac{M_{2}(y)^{2}}{\cos \varphi} d y+\frac{1}{2 E_{11(\text { tow })} A} \int_{0}^{W_{R U C}} \frac{N_{2}(y)^{2}}{\cos \varphi} d y+\frac{1}{2 G_{13(\text { tow })} A} \int_{0}^{W_{R U C}} \frac{Q_{2}(y)^{2}}{\cos \varphi} d y
\end{aligned}
$$

In the above equations the cosines of $\theta$ and $\varphi$ are, respectively, expressed as:

$$
\begin{aligned}
& \cos \theta=\frac{1}{\sqrt{1+\tan ^{2} \theta}}=\left\{\begin{array}{c}
\frac{\sqrt{r_{U}^{2}-x^{2}}}{r_{U}}, x=0 \sim \frac{1}{4} L_{R U C} \\
\frac{\sqrt{r_{U}^{2}-\left(x-\frac{1}{2} L_{R U C}\right)^{2}}}{r_{U}}, x=\frac{1}{4} L_{R U C} \sim \frac{1}{2} L_{R U C}
\end{array}\right. \\
& \cos \varphi=\frac{1}{\sqrt{1+\tan ^{2} \varphi}}=\left\{\begin{array}{c}
\frac{\sqrt{r_{U}^{2}-y^{2}}}{r_{U}}, y=0 \sim \frac{1}{4} W_{R U C} \\
\frac{\sqrt{r_{U}^{2}-\left(y-\frac{1}{2} W_{R U C}\right)^{2}}}{r_{U}}, y=\frac{1}{4} W_{R U C} \sim \frac{1}{2} W_{R U C}
\end{array}\right.
\end{aligned}
$$

The simplification functions of $C_{1}(x), C_{2}(y), S_{1}(x)$ and $S_{2}(y)$ are defined as:

$$
\begin{aligned}
& C_{1}(x)=\sqrt{r_{U^{2}}-x^{2}}, C_{2}(y)=\sqrt{r_{U^{2}}-y^{2}} \\
& S_{1}(x)=\sqrt{r_{U^{2}}-\left(x-\frac{1}{2} L_{R U C}\right)^{2}}, S_{2}(y)=\sqrt{r_{U^{2}}-\left(y-\frac{1}{2} W_{R U C}\right)^{2}}
\end{aligned}
$$

Putting the internal loads of Equations (9)-(11) into the strain energy formulation in Equation (17), $U_{1}$ could be further expressed with the simplified intermediate coefficients of $X_{1}, X_{2}, X_{31}, X_{5}, X_{6}$ and $X_{7}$ as follows, considering the symmetrical characteristics of the studied warp yarn segment:

$$
\begin{aligned}
& U_{1}=\frac{1}{E_{11(\text { tow })} I}\left\{\int_{0}^{\frac{L_{R U C}}{4}} \frac{\left\{M_{1}+N\left[r_{U}-C_{1}(x)\right]-\frac{1}{2} Q x\right\}^{2} r_{U}}{C_{1}(x)} d x\right. \\
& \left.+\int_{\frac{L_{R U C}}{4}}^{\frac{L_{R U C}}{2}} \frac{\left\{M_{1}+N\left[r_{U}-2 H+S_{1}(x)\right]-\frac{1}{2} Q x\right\}^{2} \cdot r_{U}}{S_{1}(x)} d x\right\} \\
& +\frac{1}{E_{11(\text { tow })} A}\left\{\int_{0}^{\frac{L_{R U C}}{4}} \frac{\left[2 N C_{1}(x)+Q \cdot x\right]^{2}}{4 r_{U} C_{1}(x)} d x+\int_{\frac{L_{R U C}}{4}}^{\frac{L_{R U C}}{2}} \frac{\left[2 N S_{1}(x)-Q\left(x-\frac{L_{R U C}}{2}\right)\right]^{2}}{4 r_{U} S_{1}(x)} d x\right\} \\
& +\frac{1}{G_{13(t o w)} A}\left\{\int_{0}^{\frac{L_{R U C}}{4}} \frac{\left[2 N x-Q C_{1}(x)\right]^{2}}{4 r_{U} C_{1}(x)} d x+\int_{\frac{L_{R U C}}{2}}^{\frac{L_{R U C}}{2}} \frac{\left[2 N\left(x-\frac{L_{R U C}}{2}\right)+Q S_{1}(x)\right]^{2}}{4 r_{U} S_{1}(x)} d x\right\} \\
& =M_{1}^{2} \cdot X_{1}+N^{2} \cdot X_{2}+Q^{2} \cdot X_{31}+M_{1} N \cdot X_{5}-M_{1} Q \cdot X_{6}-N Q \cdot X_{7}
\end{aligned}
$$

Similarly, for the studied weft yarn segment $U_{2}$ could be further expressed with the simplified intermediate coefficients of $X_{32}, X_{4}$ and $X_{8}$ as:

$$
\begin{aligned}
& U_{2}=\frac{1}{E_{11(\text { tow })} I}\left[\int_{0}^{\frac{W_{R U C}}{4}} \frac{\left(M_{2}+\frac{1}{2} Q y\right)^{2} r_{U}}{C_{2}(y)} d y+\int_{\frac{W_{R U C}}{2}}^{\frac{W_{R U C}}{4}} \frac{\left(M_{2}+\frac{1}{2} Q y\right)^{2} r_{U}}{S_{2}(y)} d y\right] \\
& +\frac{1}{E_{11(\text { tow })} A}\left[\int_{0}^{\frac{W_{R U C}}{4}} \frac{Q^{2} y^{2}}{4 r_{U} C_{2}(y)} d y+\int_{\frac{W_{R U C}}{W_{R U C}}}^{\frac{W_{R U C}}{2}} \frac{Q^{2}\left(y-\frac{1}{2} W_{R U C}\right)^{2}}{4 r_{U} S_{2}(y)} d y\right] \\
& +\frac{1}{G_{13(t o w)} A}\left[\int_{0}^{\frac{W_{R U C}}{4}} \frac{Q^{2} C_{2}(y)}{4 r_{U}} d y+\int_{\frac{W_{R U C}}{4}}^{\frac{W_{R U C}^{4}}{2}} \frac{Q^{2} S_{2}(y)}{4 r_{U}} d y\right] \\
& =Q^{2} \cdot X_{32}+M_{2}^{2} \cdot X_{4}+M_{2} Q \cdot X_{8}^{4}
\end{aligned}
$$


The simplified intermediate coefficients in the above equations of (23) and (24) are expressed as follows:

$$
\begin{aligned}
& X_{1}=\int_{0}^{\frac{L_{R U C}}{4}} \frac{r_{U}}{E_{11(\text { tow })} I C_{1}(x)} d x+\int_{\frac{L_{R U C}}{4}}^{\frac{L_{R U C}}{2}} \frac{r_{U}}{E_{11(\text { tow })} I S_{1}(x)} d x \\
& X_{2}=\int_{0}^{\frac{L_{R U C}}{4}}\left\{\frac{r_{U}\left[r_{U}-C_{1}(x)\right]^{2}}{E_{11(\text { tow })} I C_{1}(x)}+\frac{C_{1}(x)}{E_{11(\text { tow })} A r_{U}}+\frac{x^{2}}{G_{13(t o w)} A r_{U} C_{1}(x)}\right\} d x \\
& +\int_{\frac{L_{R U C}}{4}}^{\frac{L_{R U C}}{2}}\left\{\frac{r_{U}\left[r_{U}-2 H+S_{1}(x)\right]^{2}}{E_{11(\text { tow })} I S_{1}(x)}+\frac{S_{1}(x)}{E_{11(t o w)} A r_{U}}+\frac{\left(x-\frac{1}{2} L_{R U C}\right)^{2}}{G_{13(\text { tow })} A r_{U} S_{1}(x)}\right\} d x \\
& X_{31}=\int_{0}^{\frac{L_{R U C}}{4}}\left[\frac{r_{U} x^{2}}{4 E_{11(\text { tow })} I C_{1}(x)}+\frac{x^{2}}{4 E_{11(\text { tow })} A r_{U} C_{1}(x)}+\frac{C_{1}(x)}{4 G_{13(\text { tow })} A r_{U}}\right] d x \\
& +\int_{\frac{L_{R U C}}{4}}^{\frac{L_{R U C}}{2}}\left[\frac{r_{U} x^{2}}{4 E_{11(\text { tow })} I S_{1}(x)}+\frac{\left(x-\frac{1}{2} L_{R U C}\right)^{2}}{4 E_{11(\text { tow })} A r_{U} S_{1}(x)}+\frac{S_{1}(x)}{4 G_{13(\text { tow })} A r_{U}}\right] d x \\
& X_{32}=\int_{0}^{\frac{W_{R U C}}{4}}\left[\frac{r_{U} y^{2}}{4 E_{11(\text { tow })} I C_{2}(y)}+\frac{y^{2}}{4 E_{11(\text { tow })} A r_{U} C_{2}(y)}+\frac{C_{2}(y)}{4 G_{13(t o w)} A r_{U}}\right] d y \\
& +\int_{\frac{W_{R U C}}{4}}^{\frac{W_{R U C}}{2}}\left[\frac{r_{U} y^{2}}{4 E_{11(t o w)} I S_{2}(y)}+\frac{\left(y-\frac{1}{2} W_{R U C}\right)^{2}}{4 E_{11(\text { tow })} A r_{U} S_{2}(y)}+\frac{S_{2}(y)}{4 G_{13(t o w)} A r_{U}}\right] d y \\
& X_{4}=\int_{0}^{\frac{W_{R U C}}{4}} \frac{r_{U}}{E_{11(\text { tow })} I C_{2}(y)} d y+\int_{\frac{W_{R U C}}{4}}^{\frac{W_{R U C}}{2}} \frac{r_{U}}{E_{11(\text { tow })} I S_{2}(y)} d y \\
& X_{5}=\int_{0}^{\frac{L_{R U C}}{4}} \frac{2 r_{U}\left[r_{U}-C_{1}(x)\right]}{E_{11(\text { tow })} I C_{1}(x)} d x+\int_{\frac{L_{R U C}}{4}}^{\frac{L_{R U C}}{2}} \frac{2 r_{U}\left[r_{U}-2 H+S_{1}(x)\right]}{E_{11(\text { tow })} I S_{1}(x)} d x \\
& X_{6}=\int_{0}^{\frac{L_{R U C}}{4}} \frac{r_{U} x}{E_{11(\text { tow })} I C_{1}(x)} d x+\int_{\frac{L_{R U C}}{4}}^{\frac{L_{R U C}}{2}} \frac{r_{U} x}{E_{11(\text { tow })} I S_{1}(x)} d x \\
& X_{7}=\int_{0}^{\frac{L_{R U C}}{4}}\left\{\frac{r_{U} x\left[r_{U}-C_{1}(x)\right]}{E_{11(\text { tow })} I C_{1}(x)}-\frac{x}{E_{11(\text { tow })} A r_{U}}+\frac{x}{G_{13(\text { tow })} A r_{U}}\right\} d x \\
& +\int_{\frac{L_{R U C}}{4}}^{\frac{L_{R U C}}{2}}\left\{\frac{r_{U} x\left[r_{U}-2 H+S_{1}(x)\right]}{E_{11(\text { tow })} I S_{1}(x)}+\frac{x-\frac{1}{2} L_{R U C}}{E_{11(\text { tow })} A r_{U}}-\frac{x-\frac{1}{2} L_{R U C}}{G_{13(\text { tow })} A r_{U}}\right\} d x \\
& X_{8}=\int_{0}^{\frac{W_{R U C}}{4}} \frac{r_{U} y}{E_{11(\text { tow })} I C_{2}(y)} d y+\int_{\frac{W_{R U C}}{4}}^{\frac{W_{R U C}}{2}} \frac{r_{U} y}{E_{11(\text { tow })} I S_{2}(y)} d y
\end{aligned}
$$

By defining the intermediate coefficient of $X_{3}$ as:

$$
X_{3}=X_{31}+X_{32}
$$

the total strain energy, $U$, for the part of the fiber tows in the mesoscale RUC of Figure 2 could then be obtained as:

$U=2\left(U_{1}+U_{2}\right)$
$=2\left(M_{1}^{2} \cdot X_{1}+N^{2} \cdot X_{2}+Q^{2} \cdot X_{3}+M_{2}^{2} \cdot X_{4}+M_{1} N \cdot X_{5}-M_{1} Q \cdot X_{6}-N Q \cdot X_{7}+M_{2} Q \cdot X_{8}\right)$

Constraint at the left end, the right end's displacement of the deformed warp yarn segment along the $\mathrm{X}$-axis corresponding to the axial tensile load of $N$ is presented as $u_{1}$ in Figure 6.

For the studied warp yarn segment in Figure $2 U_{1}^{*}$ stands for its complementary energy. According to Castigliano's second theorem:

$$
u_{1}=\frac{\partial U_{1}^{*}}{\partial N}
$$




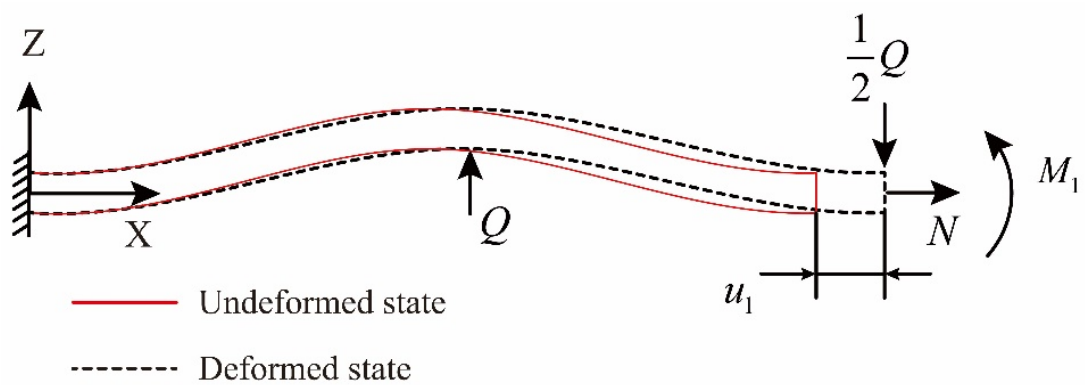

Figure 6. X-directional deformation of the deformed warp yarn segment.

Within the framework of the ideal linear elasticity $U_{1} *$ is equal to the strain energy $U_{1}$, and $u_{1}$ in Figure 6 could be expressed as:

$$
\begin{aligned}
& u_{1}=\frac{\partial U_{1}}{\partial N} \\
& =\int_{0}^{L_{R U C}} \frac{M_{1}(x)}{E_{11(\text { tow }) ~ I \cos \theta}} \cdot \frac{\partial M_{1}(x)}{\partial N} d x+\int_{0}^{L_{R U C}} \frac{N_{1}(x)}{E_{11(\text { tow })} A \cos \theta} \cdot \frac{\partial N_{1}(x)}{\partial N} d x \\
& +\int_{0}^{L_{R U C}} \frac{Q_{1}(x)}{G_{13(t o w)} A \cos \theta} \cdot \frac{\partial Q_{1}(x)}{\partial N} d x \\
& =2 X_{2} N+X_{5} M_{1}-X_{7} Q
\end{aligned}
$$

The constraint moments of $M_{1}$ and $M_{2}$ and the interaction load of $Q$ are all introduced by $N$, which is the only external load applied to warp yarn in the monolayer of the plainwoven fabric composites. Under the linear hypothesis within the small deformation extents the constraint moments and the interaction load are supposed linearly correlated with the external load, $N$, through the coefficients of $k_{1}, k_{2}$ and $k_{3}$ :

$$
\begin{gathered}
M_{1}=k_{1} \cdot N \\
M_{2}=k_{2} \cdot N \\
Q=k_{3} \cdot N
\end{gathered}
$$

Putting Equations (38)-(40) into Equation (35), the total strain energy of $U$ then turns into:

$$
U=2\left(k_{1}^{2} X_{1}+X_{2}+k_{3}^{2} X_{3}+k_{2}^{2} X_{4}+k_{1} X_{5}-k_{1} k_{3} X_{6}-k_{3} X_{7}+k_{2} k_{3} X_{8}\right) \cdot N^{2}
$$

For the part of fiber tows in the mesoscale RUC of Figure 2, the total potential energy is defined as $\Pi$ and the external work is defined as $W$. Considering the total strain energy of $U$, $\Pi$ could be expressed as:

$$
\Pi=U-W
$$

According to the principle of minimum potential energy, among all the displacement solutions which satisfy the geometric boundary conditions the real displacement solution minimizes the structural total potential energy. Corresponding to the minimum total potential energy, $\Pi_{\min }$, under real structural displacement the reasonable choice of the coefficients $k_{1}, k_{2}$ and $k_{3}$ minimizes the total strain energy, $U$, which leads to:

$$
\frac{\partial U}{\partial k_{i}}=0, i=1 \sim 3
$$

The coefficients of $k_{1}, k_{2}$ and $k_{3}$ are then determined as:

$$
k_{1}=\frac{\frac{X_{7} X_{6}}{2 X_{1}}-\frac{X_{5} X_{6}^{2}}{4 X_{1}^{2}}}{2 X_{3}-\frac{X_{6}{ }^{2}}{2 X_{1}}-\frac{X_{8}^{2}}{2 X_{4}}}-\frac{X_{5}}{2 X_{1}}
$$




$$
\begin{gathered}
k_{2}=\frac{\left(\frac{X_{5} X_{6}}{2 X_{1}}-X_{7}\right) X_{8}}{\left(4 X_{3}-\frac{X_{6}{ }^{2}}{X_{1}}-\frac{X_{8}{ }^{2}}{X_{4}}\right) X_{4}} \\
k_{3}=\frac{X_{7}-\frac{X_{5} X_{6}}{2 X_{1}}}{2 X_{3}-\frac{X_{6}{ }^{2}}{2 X_{1}}-\frac{X_{8}^{2}}{2 X_{4}}}
\end{gathered}
$$

The relationships in Equations (38)-(40) with $k_{1}, k_{2}$ and $k_{3}$ in Equations (44)-(46) could also be deduced from the principle of the minimum complementary energy as presented in Equations (47)-(49), indicating the rationality of the linear hypothesis:

$$
\begin{aligned}
& \frac{\partial U_{1}{ }^{*}}{\partial M_{1}}=0 \\
& \frac{\partial U_{1}{ }^{*}}{\partial M_{2}}=0 \\
& \frac{\partial U_{1}{ }^{*}}{\partial Q}=0
\end{aligned}
$$

Considering Equations (44)-(46) and putting Equations (38)-(40) into Equation (37), the relationship between $u_{1}$ and $N$ in Figure 6 could be further determined with the intermediate coefficient of $X_{9}$ :

$$
u_{1}=X_{9} N
$$

where:

$$
X_{9}=2 X_{2}-\frac{X_{5}^{2}}{2 X_{1}}+\frac{2 X_{5} X_{6} X_{7}-2 X_{1} X_{7}^{2}-\frac{X_{5}^{2} X_{6}^{2}}{2 X_{1}}}{4 X_{1} X_{3}-X_{6}^{2}-\frac{X_{1} X_{8}^{2}}{X_{4}}}
$$

The part composed of fiber tows in the mesoscale RUC is isolated and studied in Figure 7. With the left-end constraint the displacement of the loading end reaches $u_{1}$ under the total axial tension of $2 \mathrm{~N}$ loaded at the cross-sections of the warp yarns with the area of $2 A$, corresponding to the result of the single warp yarn segment in Figure 6.

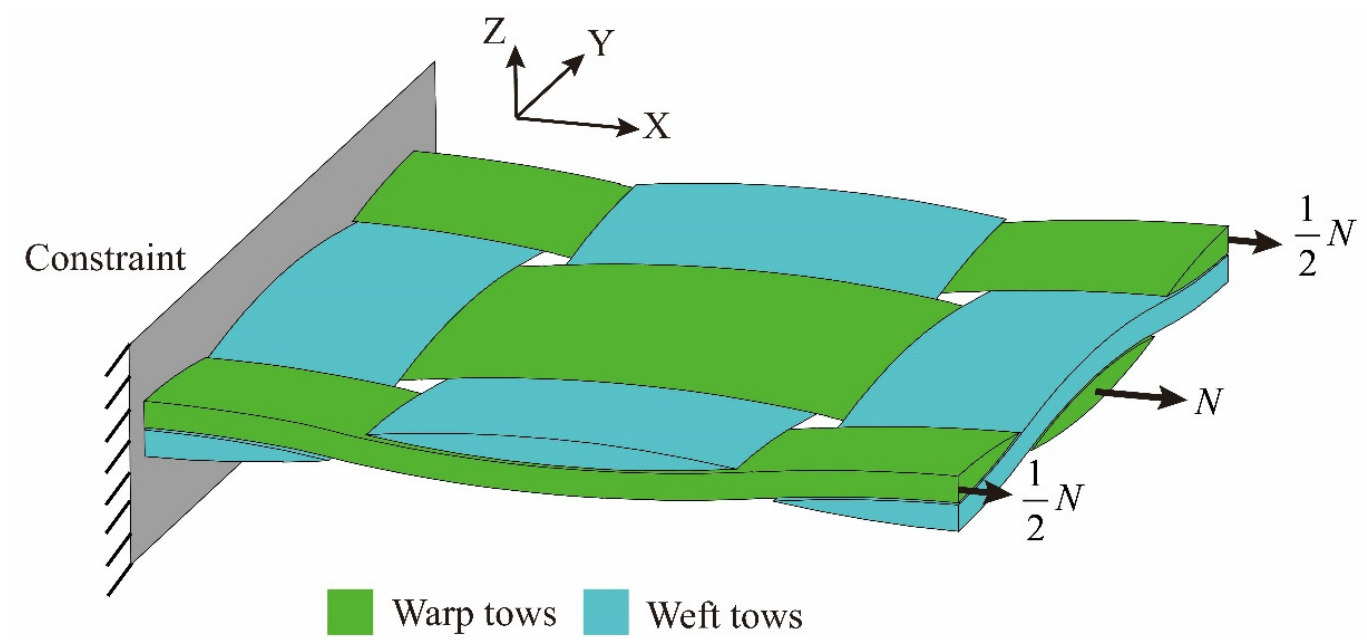

Figure 7. The part composed of fiber tows in the mesoscale RUC of the plain-woven fabric composites.

For the studied part in Figure 7, define the equivalent modulus along the $\mathrm{X}$-axis as $E_{t t}$ and $u_{1}$ could be expressed as:

$$
u_{1}=\frac{N L_{R U C}}{E_{t t} A}
$$


Put Equation (50) into Equation (52) and the modulus of $E_{t t}$ is determined as:

$$
E_{t t}=\frac{L_{R U C}}{X_{9} A}
$$

$E_{m}$ stands for the elastic modulus of the matrix and $V_{t}$ stands for the volume fraction of the tows in the plain-woven fabric composites. Based on the rule of mixtures, the uniaxial tensile modulus, $E_{11}$, of the plain-woven fabric composites could be expressed as:

$$
\begin{aligned}
& E_{11}=E_{t t} V_{t}+E_{m}\left(1-V_{t}\right) \\
& =\frac{L_{R U C}}{X_{9} A} \cdot V_{t}+E_{m}\left(1-V_{t}\right)
\end{aligned}
$$

With the above deductions, the proposed analytical model for the uniaxial tensile modulus of the plain-woven fabric composites is illustrated in Figure 8. Based on the experimental observations, the necessary geometric parameters of the fiber tows and the RUC, including $a, b, r_{U}$ and $L_{R U C}$, are first obtained as inputs. The corresponding cross-section area of $A$ and the inertia moment of $I$ are subsequently calculated. Series of experiments including the thermal ablation of the laminates and microscopic observations are needed in order to achieve the fiber volume fraction in tows, $V_{f}$, and the volume fraction of tows, $V_{t}$. Besides, parameters of the elastic modulus of the matrix, $E_{m}$, the shear modulus of the matrix, $G_{m}$, the in-plane shear modulus of the fiber, $G_{f 12}$, and the longitudinal modulus of the fiber, $E_{f 11}$, need to be obtained, with which the longitudinal modulus of $E_{11(\text { tow })}$ and the out-of-plane shear modulus of $G_{13 \text { (tow) }}$ for the fiber tows could be calculated through the Chamis equations:

$$
\begin{aligned}
& E_{11(\text { tow })}=V_{f} E_{f 11}+\left(1-V_{f}\right) E_{m} \\
& G_{13(\text { tow })}=\frac{G_{m}}{1-\sqrt{V_{f}}\left(1-\frac{G_{m}}{G_{f 12}}\right)}
\end{aligned}
$$

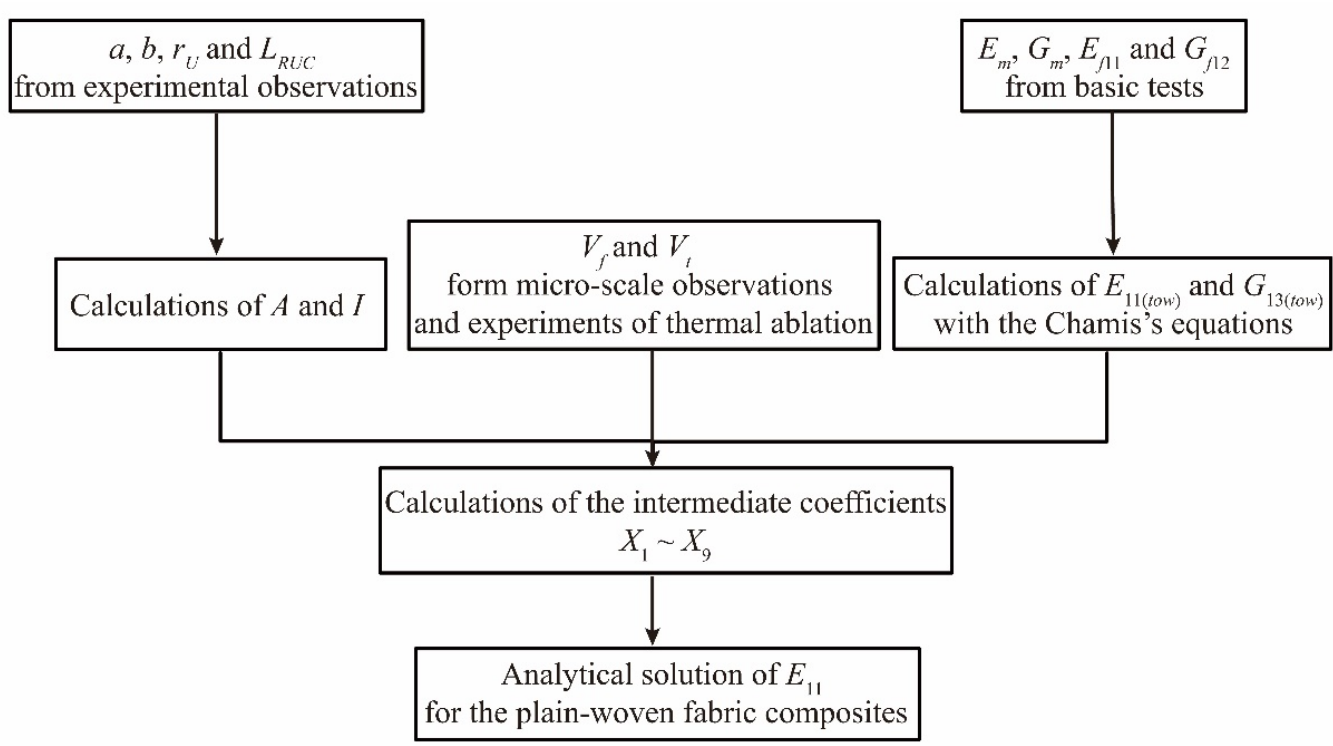

Figure 8. Flowchart of the analytical model for the uniaxial tensile modulus of the plain-woven fabric composites.

Subsequently, the intermediate coefficients of $X_{1}-X_{9}$ could be achieved and the uniaxial tensile modulus of $E_{11}$ is analytically solved. Using the platform of an Intel Core i7-9750H CPU, the single run time of the analytical model in calculating $E_{11}$ is $2 \mathrm{~s}$ with the necessary inputs prepared. 


\section{Application of the Analytical Model and the Experimental Validation}

The plain-woven fabric composite of T300/Cycom970 is chosen as the study object in this article and the uniaxial tensile modulus of $E_{11}$ is predicted with the method proposed above. The mechanical properties of the T300 carbon fiber and the Cycom970 epoxy matrix [31] are presented in Table 1.

Table 1. Mechanical properties of the fiber and matrix constituents in the T300/Cycom970 composite.

\begin{tabular}{ccc}
\hline Constituent & Material Property & Value \\
\hline & Longitudinal modulus, $E_{f 11}(\mathrm{GPa})$ & 230.00 \\
& Transverse modulus, $E_{f 22}=E_{f 33}(\mathrm{GPa})$ & 13.80 \\
& In-plane shear modulus, $\mathrm{G}_{f 12}(\mathrm{GPa})$ & 8.97 \\
& Out-of-plane shear modulus, $\mathrm{G}_{f 13}(\mathrm{GPa})$ & 8.97 \\
& Out-of-plane shear modulus, $\mathrm{G}_{f 23}(\mathrm{GPa})$ & 4.38 \\
& In-plane Poisson's ratio, $v_{f 12}$ & 0.20 \\
& Out-of-plane Poisson's ratio, $v_{f 13}$ & 0.20 \\
& Out-of-plane Poisson's ratio, $v_{f 23}$ & 0.25 \\
& Density, $\rho_{f}\left(\mathrm{~g} / \mathrm{cm}^{3}\right)$ & 1.76 \\
\hline \multirow{3}{*}{ Matrix $($ Cycom970) } & Elastic modulus, $E_{m}(\mathrm{GPa})$ & 3.35 \\
& Elastic Poisson's ratio, $v_{m}$ & 0.35 \\
& Density, $\rho_{m}\left(\mathrm{~g} / \mathrm{cm}^{3}\right)$ & 1.24 \\
\hline
\end{tabular}

Specimens of T300/Cycom970 laminates with a stacking sequence of [0] $]_{16}$ and dimensions of $25 \mathrm{~mm} \times 25 \mathrm{~mm} \times 3.456 \mathrm{~mm}$ are manufactured and scanned first with micro-CT equipment to achieve the necessary geometric parameters. As a carbon fiber/epoxy composite, the similar atomic numbers of the fiber and the matrix in the T300/Cycom970 laminates lead to a small difference in the components' $\mathrm{X}$-ray absorption rates. In order to solve the blurry imaging problem micro-CT equipment with a high-resolution lens-coupled detector is utilized in the current scanning. A typical $Y-Z$ slice image of the fabric laminate is illustrated in Figure 9 and the statistical average values of $a, b, r_{U}$ and $L_{R U C}$ from different samples of sections are presented in Table 2, together with the corresponding $A$ and $I$.

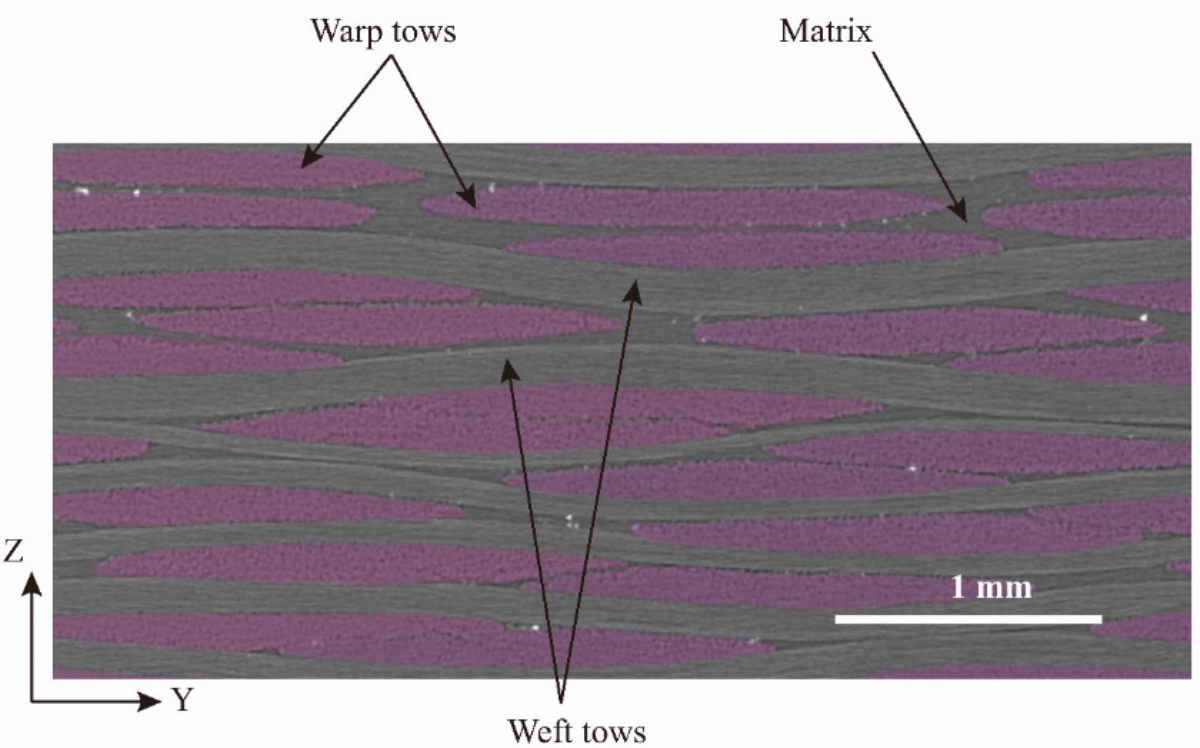

Figure 9. A typical Y-Z slice image of the T300/Cycom970 plain-woven fabric composite. 
Table 2. Geometric parameters of fiber tows in the T300/Cycom970 plain-woven fabric composite.

\begin{tabular}{cc}
\hline Geometric Parameter & Value \\
\hline Width of the fiber tows' lenticular cross-section, $a(\mathrm{~mm})$ & 1.82 \\
Thickness of the fiber tows' lenticular cross-section, $b(\mathrm{~mm})$ & 0.13 \\
Radius of the arcs in fiber tows' undulation path, $r_{U}(\mathrm{~mm})$ & 7.18 \\
Length of the mesoscale RUC, $L_{R U C}(\mathrm{~mm})$ & 4.00 \\
Area of the fiber tows' lenticular cross-section, $A\left(\mathrm{~mm}^{2}\right)$ & 0.16 \\
Inertia of the fiber tows' lenticular cross-section, $I\left(10^{-4} \mathrm{~mm}^{4}\right)$ & 1.67 \\
\hline
\end{tabular}

Thermal ablation experiments have been conducted on the specimens under the ASTM Standard D3171 [32]-based procedure in order to separate the component of the fiber from the matrix and obtain the total fiber volume fraction of $V_{f T}$. The specimens are first weighed with an electronic balance and the initial weight of $m_{0}$ for each specimen is achieved. After heating with a chamber furnace under a temperature of $600{ }^{\circ} \mathrm{C}$ for four hours, as shown in Figure 10, the epoxy matrix component in the specimens is totally ablated and the residual weight of fibers, $m_{f}$, for each specimen is recorded. For each of the specimens, with the densities of the matrix $\left(\rho_{m}\right)$ and the carbon fiber $\left(\rho_{f}\right)$ presented in Table 1, the total fiber volume fraction, $V_{f T}$, of the plain-woven fabric composite could be obtained as:

$$
V_{f T}=\frac{m_{f} \cdot \rho_{m}}{m_{f} \cdot \rho_{m}+\left(m_{0}-m_{f}\right) \cdot \rho_{f}}
$$

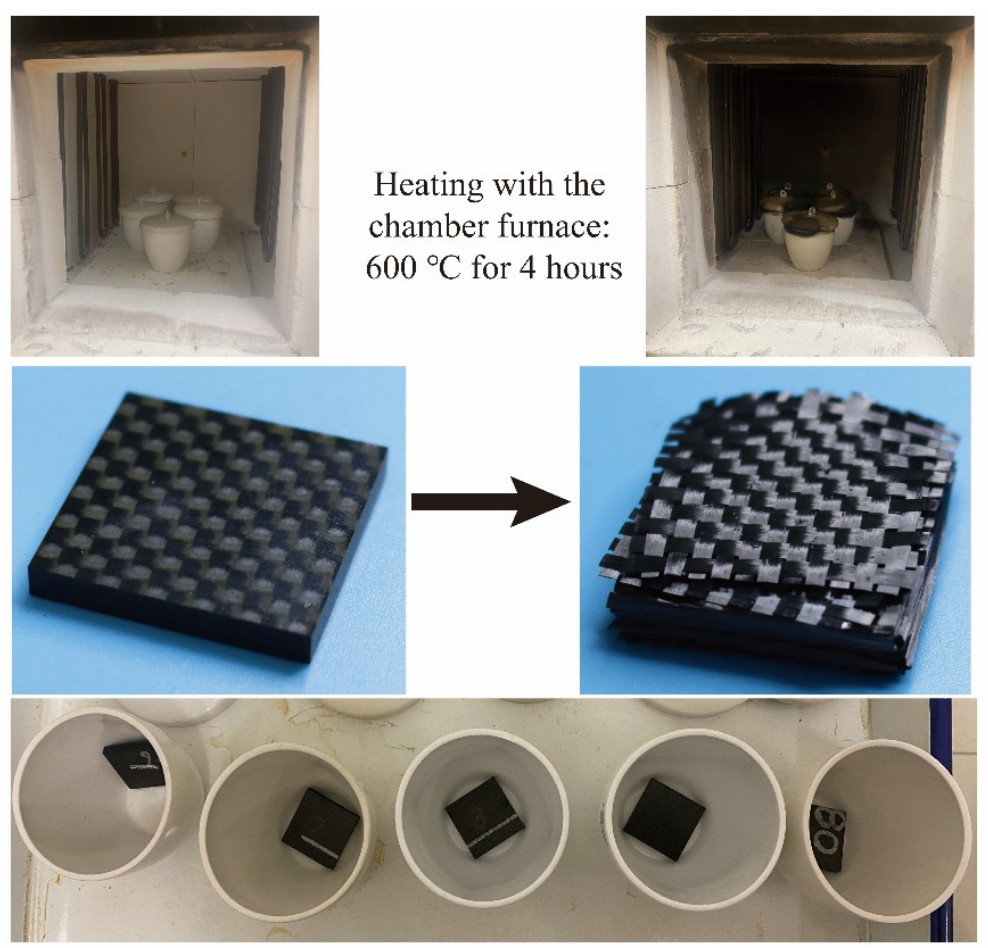

Figure 10. Thermal ablation experiments on the specimens of T300/Cycom 970 fabric laminates.

The results of the thermal ablation experiments on the specimens, numbered one-five, are presented in Table 3. For the studied composite of T300/Cycom970, $V_{f T}$ is determined as the statistical average value of the experimental results.

In obtaining the fiber volume fraction in tows of $V_{f}$, microscopic observations have been conducted on the plain-woven fabric composites. In order to achieve ideal observation results focused ion beam (FIB) polishing has been conducted on the specimen, and the regions of the fiber tows' cross-sections are then observed with a scanning electron microscope (SEM), as shown in Figure 11. Within a fixed observation area the regions of 
the fiber sections are distinguished from the adjacent matrix regions through further digital image processing of the observation result. $A_{f}$ and $A_{m}$, which represent the area of the fibers and the area of the matrix, respectively, are achieved, and the regional fiber volume fraction, which is equal to the area ratio of $A_{f} /\left(A_{f}+A_{m}\right)$, is then calculated. A typical microscopic observation on the cross-section of the fiber tows and the corresponding digital image processing result are presented in Figure 11, and the value of $V_{f}$ for the plain-woven fabric composite is determined as the statistical average value of the obtained different regional fiber volume fractions.

Table 3. Results of the thermal ablation experiments.

\begin{tabular}{cccc}
\hline Specimen & Initial Weight $m_{0}(\mathbf{g})$ & $\begin{array}{c}\text { Residual Weight } m_{\boldsymbol{f}} \\
(\mathbf{g})\end{array}$ & $\begin{array}{c}\text { Total Fiber Volume } \\
\text { Fraction } V_{\boldsymbol{f} \boldsymbol{T}}\end{array}$ \\
\hline No. 1 & 3.21 & 2.07 & 0.56 \\
No. 2 & 3.23 & 2.09 & 0.56 \\
No. 3 & 3.22 & 2.04 & 0.55 \\
No. 4 & 3.20 & 2.05 & 0.56 \\
No. 5 & 3.20 & 2.05 & 0.56 \\
\hline
\end{tabular}
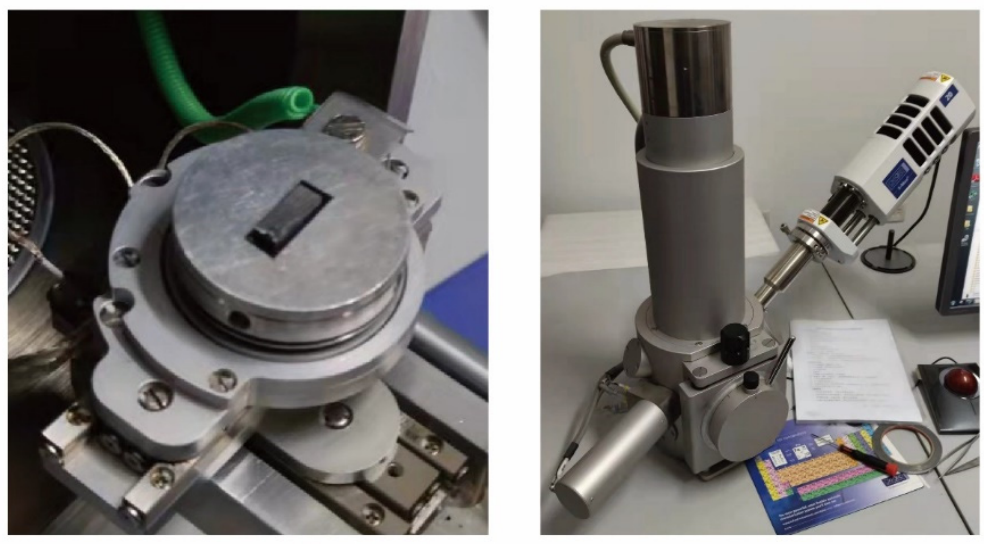

SEM-based microscopic observation on the specimen of plain-woven fabric composites

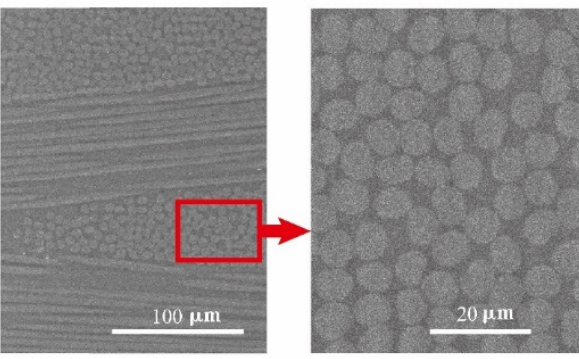

Microscopic observation on the cross-section of fiber tows

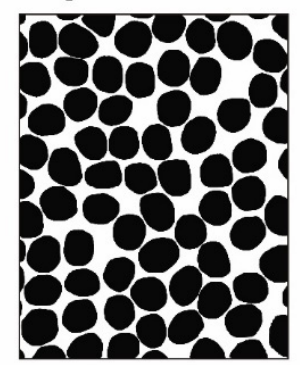

Digital image processing in dividing the regions of fiber and matrix

Figure 11. Microscopic observation of the specimen of plain-woven fabric composites and digital image processing for the SEM observation result.

According to the Equation (58) the volume fraction of tows, $V_{t}$, of the T300/Cycom970 fabric composite could be obtained with $V_{f T}$ and $V_{f}$ :

$$
V_{t}=\frac{V_{f T}}{V_{f}}
$$

The finally determined values of $V_{f T}, V_{f}$ and $V_{t}$ are listed in Table 4 . Based on the fiber volume fraction in tows of $V_{f}$ and the constituents' properties in Table 1, the calculations 
of the fiber tows' mechanical properties based on the Chamis equations are presented in Table 5 .

Table 4. Volume fraction parameters of the T300/Cycom970 plain-woven fabric composite.

\begin{tabular}{cc}
\hline Parameter & Value \\
\hline Total fiber volume fraction, $V_{f T}$ & 0.56 \\
Fiber volume fraction in tows, $V_{f}$ & 0.78 \\
Volume fraction of tows, $V_{t}$ & 0.72 \\
\hline
\end{tabular}

Table 5. Mechanical properties of the fiber tows in the T300/Cycom970 plain-woven fabric composite.

\begin{tabular}{cc}
\hline Property & Value \\
\hline Longitudinal modulus, $E_{11(\text { tow })}(\mathrm{GPa})$ & 180.24 \\
Transverse modulus, $E_{22(\text { tow })}=E_{33(\text { tow })}(\mathrm{GPa})$ & 10.27 \\
In-plane shear modulus, $G_{12(\text { tow })}(\mathrm{GPa})$ & 9.66 \\
Out-of-plane shear modulus, $\mathrm{G}_{13(\text { tow })}(\mathrm{GPa})$ & 9.66 \\
Out-of-plane shear modulus, $\mathrm{G}_{23(\text { tow })}(\mathrm{GPa})$ & 3.78 \\
\hline
\end{tabular}

With the above inputs the intermediate coefficients of $X_{1}-X_{9}$ are calculated according to the flowchart illustrated in Figure 8, and the result of $E_{11}$ for the T300/Cycom970 plain-woven fabric composite is predicted as 54.39 MPa.

Tensile experiments have been performed on the laminates made of T300/Cycom970 plain-woven fabrics. The experimental result is compared with the above prediction of $E_{11}$ in order to validate the proposed analytical model.

Considering the purpose of validation, the manufacturing process of the composite laminates has been intentionally controlled to enhance the specimens' consistency and reduce the effects of uncertainty. The specimens with a stacking sequence of $[0]_{16}$ and dimensions of $250 \mathrm{~mm} \times 25 \mathrm{~mm} \times 3.456 \mathrm{~mm}$ are shown in Figure 12, which are tested by an electronic universal testing machine with a maximum loading capacity of $100 \mathrm{kN}$. Six specimens numbered CL-1-01 to CL-1-06 have been tested under the ASTM Standard D3039M-17 [33]-based procedure. Subjected to tensile loading, the stress-strain curves of the specimens have been achieved, with longitudinal strain results obtained from the strain gages. For two different points on the stress-strain curve, the difference in the applied tensile stress is defined as $\Delta \sigma$ and the difference between the strains is defined as $\Delta \varepsilon$. Stress-strain data within the lower half of the stress-strain curves are utilized ito calculate the uniaxial tensile modulus of $E_{11}$ :

$$
E_{11}=\frac{\Delta \sigma}{\Delta \varepsilon}
$$

In Table 6 the experimental $E_{11}$ of the specimens is listed, along with the average value, the standard deviation and the coefficient of dispersion. The small values of the standard deviation and the coefficient of dispersion indicate the good repeatability of the experimental results. With neglectable effects of uncertainty, the specimens behave well in the aspect of validation. Compared to the average value of the experimental $E_{11}$ the calculation result from the analytical model of $54.39 \mathrm{MPa}$ has a deviation of $-4.33 \%$. The small deviation validates the effectiveness of the analytical model in predicting the unidirectional tensile modulus of the plain-woven fabric composites and further indicates the rationality of the inputs of the experimentally obtained geometric and mechanical parameters, which could be utilized in the establishment of the composites' mesoscale RUC. 


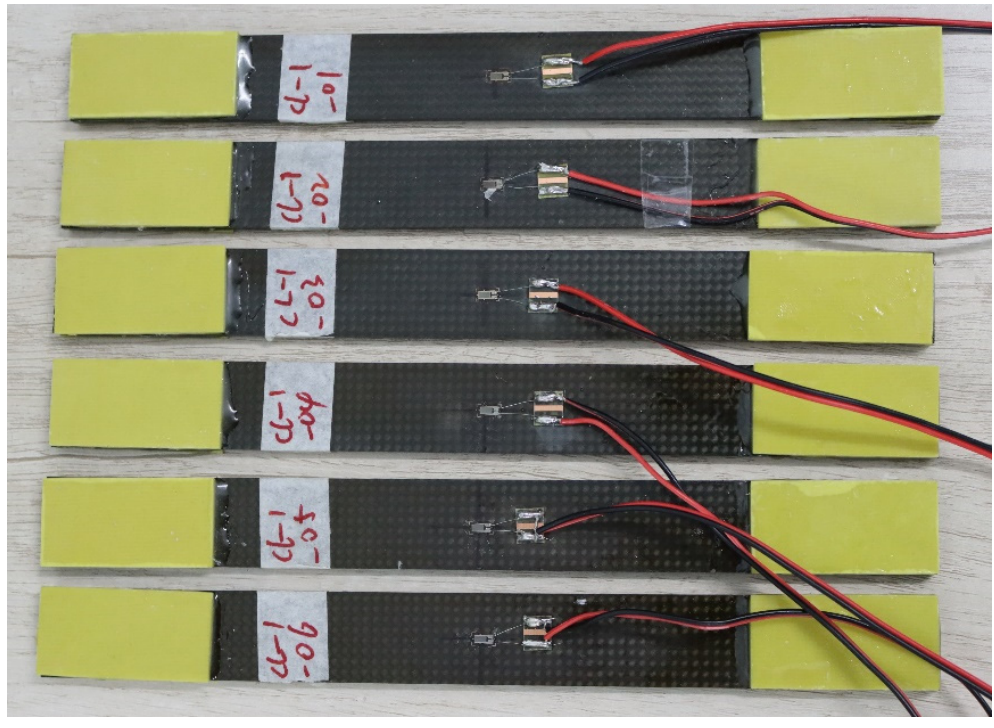

Figure 12. Tensile specimens of the T300/Cycom 970 fabric laminates.

Table 6. Experimental uniaxial tensile modulus of the T300/Cycom970 fabric laminates and comparison with the analytical solution.

\begin{tabular}{ccccccc}
\hline Specimen & $\begin{array}{c}\text { Experimental } \\
\boldsymbol{E}_{\mathbf{1 1}}(\mathrm{GPa})\end{array}$ & $\begin{array}{c}\text { Average } \\
\text { Value } \\
\mathbf{( G P a )}\end{array}$ & $\begin{array}{c}\text { Standard } \\
\text { Deviation } \\
\mathbf{( G P a )}\end{array}$ & $\begin{array}{c}\text { Coefficient of } \\
\text { Dispersion } \\
\mathbf{( \% )}\end{array}$ & $\begin{array}{c}\text { Analytical } \\
\text { Solution of } \\
\boldsymbol{E}_{\mathbf{1 1}} \mathbf{( G P a )}\end{array}$ & $\begin{array}{c}\text { Relative } \\
\text { Deviation } \\
\mathbf{( \% )}\end{array}$ \\
\hline CL-1-01 & 57.35 & & & & & \\
CL-1-02 & 57.21 & & & & & \\
CL-1-03 & 56.52 & 56.85 & 0.72 & 1.27 & 54.39 & -4.33 \\
CL-1-04 & 56.21 & & & & & \\
CL-1-05 & 55.85 & & & & & \\
CL-1-06 & 57.96 & & & & & \\
\hline
\end{tabular}

\section{Conclusions}

(1) With a solid theoretical foundation and validated by tensile experiments on the laminates, the analytical model based on the energy principles has a small margin of error and a high calculation efficiency. The model provides a new and effective method to predict the uniaxial tensile modulus of plain-woven fabric composites.

(2) The matched experiments were designed to obtain inputs for the analytical model and were conducted to predict the uniaxial tensile modulus of the T300/Cycom970 composite. The experimental procedure provides a reference for the further study of PWF composites' geometric and mechanical properties.

(3) The proposed analytical model relies heavily on the inputs obtained from experimental methods; the costly experiments limit the wide application of the analytical model to some extent. Besides, the cross-section of fiber tows and the interaction between the warp and weft yarns are simplified in the analytical model for the convenience of the analyses. Although the current margin of error is experimentally validated a more comprehensive and detailed consideration of the fiber tows' geometric characteristics and internal interactions is still needed in further research.

(4) With the advantages in efficiently validating the choosing of the fiber tows' geometric and mechanical parameters, the analytical model has good application prospects in guiding the mesoscale modeling of plain-woven fabric composites. In future work the mesoscale RUC will be built on the current basis and multiscale failure analyses could be further carried out on the T300/Cycom970 PWF composite laminates and structures. 


\begin{abstract}
Author Contributions: Conceptualization, R.Z. and W.G.; methodology, W.L. and J.X.; software, R.Z.; validation, R.Z., W.L. and W.G.; formal analysis, R.Z.; investigation, R.Z.; resources, W.G. and J.X.; data curation, W.L.; writing-original draft preparation, R.Z.; writing-review and editing, W.G.; visualization, W.L.; supervision, R.Z.; project administration, R.Z. All authors have read and agreed to the published version of the manuscript.
\end{abstract}

Funding: This research received no external funding.

Data Availability Statement: Not applicable.

Acknowledgments: The first author would like to thank Xing Li for the thermal ablation experiments in this paper.

Conflicts of Interest: The authors declare no conflict of interest.

\title{
References
}

1. Naouar, N.; Vidal-Sallé, E.; Schneider, J.; Maire, E.; Boisse, P. Meso-scale FE analyses of textile composite reinforcement deformation based on X-ray computed tomography. Compos. Struct. 2014, 116, 165-176. [CrossRef]

2. Zheng, T.; Zhang, X.; Zhao, Z.; Wu, Z.; Li, T. Geometric structure model of plain woven fabric based on progressive spring-slide mechanics. Text. Res. J. 2014, 84, 1803-1819. [CrossRef]

3. Wang, H.; Wang, Z.-W. Statistical Analysis of Yarn Feature Parameters in C/Epoxy Plain-Weave Composite Using Micro CT with High-Resolution Lens-Coupled Detector. Appl. Compos. Mater. 2016, 23, 601-622. [CrossRef]

4. De Carvalho, N.; Pinho, S.; Robinson, P. An experimental study of failure initiation and propagation in 2D woven composites under compression. Compos. Sci. Technol. 2011, 71, 1316-1325. [CrossRef]

5. Nguyen, M.; Herszberg, I.; Paton, R. The shear properties of woven carbon fabric. Compos. Struct. 1999, 47, 767-779. [CrossRef]

6. Kim, H.J.; Swan, C.C. Voxel-based meshing and unit-cell analysis of textile composites. Int. J. Numer. Methods Eng. 2003, 56, 977-1006. [CrossRef]

7. Doitrand, A.; Fagiano, C.; Irisarri, F.-X.; Hirsekorn, M. Comparison between voxel and consistent meso-scale models of woven composites. Compos. Part A Appl. Sci. Manuf. 2015, 73, 143-154. [CrossRef]

8. Grail, G.; Hirsekorn, M.; Wendling, A.; Hivet, G.; Hambli, R. Consistent Finite Element mesh generation for meso-scale modeling of textile composites with preformed and compacted reinforcements. Compos. Part A Appl. Sci. Manuf. 2013, 55, 143-151. [CrossRef]

9. Goyal, D.; Tang, X.; Whitcomb, J.D.; Kelkar, A.D. Effect of Various Parameters on Effective Engineering Properties of $2 \times 2$ Braided Composites. Mech. Adv. Mater. Struct. 2005, 12, 113-128. [CrossRef]

10. Matveev, M.; Long, A.; Jones, I. Modelling of textile composites with fibre strength variability. Compos. Sci. Technol. 2014, 105, 44-50. [CrossRef]

11. Wehrkamp-Richter, T.; De Carvalho, N.V.; Pinho, S. A meso-scale simulation framework for predicting the mechanical response of triaxial braided composites. Compos. Part A Appl. Sci. Manuf. 2018, 107, 489-506. [CrossRef]

12. Le Page, B.; Guild, F.; Ogin, S.; Smith, P. Finite element simulation of woven fabric composites. Compos. Part A Appl. Sci. Manuf. 2004, 35, 861-872. [CrossRef]

13. Obert, E.; Daghia, F.; Ladevèze, P.; Ballere, L. Micro and meso modeling of woven composites: Transverse cracking kinetics and homogenization. Compos. Struct. 2014, 117, 212-221. [CrossRef]

14. Zhou, Y.; Lu, Z.; Yang, Z. Progressive damage analysis and strength prediction of 2D plain weave composites. Compos. Part B Eng. 2013, 47, 220-229. [CrossRef]

15. Gosse, J.; Christensen, S. Strain invariant failure criteria for polymers in composite materials. In Proceedings of the 19th AIAA Applied Aerodynamics Conference, Fluid Dynamics and Co-located Conferences, Anaheim, CA, USA, 11-14 June 2001. [CrossRef]

16. Mayes, J.; Hansen, A.C. Composite laminate failure analysis using multicontinuum theory. Compos. Sci. Technol. 2004, 64, 379-394. [CrossRef]

17. Ha, S.K.; Jin, K.K.; Huang, Y. Micro-Mechanics of Failure (MMF) for Continuous Fiber Reinforced Composites. J. Compos. Mater. 2008, 42, 1873-1895. [CrossRef]

18. Ha, S.K.; Huang, Y.; Han, H.H.; Jin, K.K. Micromechanics of Failure for Ultimate Strength Predictions of Composite Laminates. J. Compos. Mater. 2010, 44, 2347-2361. [CrossRef]

19. Li, X.; Guan, Z.; Li, Z.; Liu, L. A new stress-based multi-scale failure criterion of composites and its validation in open hole tension tests. Chin. J. Aeronaut. 2014, 27, 1430-1441. [CrossRef]

20. Lou, X.; Han, X.; Cai, H. A high-efficient model for interface debonding analysis of carbon fiber-reinforced polymer composite. Compos. Interfaces 2019, 27, 87-109. [CrossRef]

21. Zhao, C.; Huang, Y.; Chen, Z.; Ha, S.K. Progressive failure prediction of a landing gear structure of braided composites. Compos. Struct. 2017, 161, 407-418. [CrossRef]

22. Xu, L.; Jin, C.Z.; Ha, S.K. Ultimate strength prediction of braided textile composites using a multi-scale approach. J. Compos. Mater. 2014, 49, 477-494. [CrossRef] 
23. Wang, M.; Zhang, P.; Fei, Q.; Guo, F. Modified micro-mechanics based multiscale model for progressive failure prediction of 2D twill woven composites. Chin. J. Aeronaut. 2020, 33, 2070-2087. [CrossRef]

24. Xiong, J.; Shenoi, R.; Cheng, X. A modified micromechanical curved beam analytical model to predict the tension modulus of 2D plain weave fabric composites. Compos. Part B Eng. 2009, 40, 776-783. [CrossRef]

25. Sheng, S.Z.; Van Hoa, S. Three Dimensional Micro-Mechanical Modeling of Woven Fabric Composites. J. Compos. Mater. 2001, 35, 1701-1729. [CrossRef]

26. Sun, H.; Pan, N. Shear deformation analysis for woven fabrics. Compos. Struct. 2005, 67, 317-322. [CrossRef]

27. Basit, M.M.; Luo, S.-Y. A simplified model of plain weave fabric reinforcements for the pure shear loading. Int. J. Mater. Form. 2018, 11, 445-453. [CrossRef]

28. Cheng, X.; Xiong, J.; Bai, J. Analytical Solution for Predicting In-plane Elastic Shear Properties of 2D Orthogonal PWF Composites. Chin. J. Aeronaut. 2012, 25, 575-583. [CrossRef]

29. Nguyen, Q.; Vidal-Sallé, E.; Boisse, P.; Park, C.H.; Saouab, A.; Bréard, J.; Hivet, G. Mesoscopic scale analyses of textile composite reinforcement compaction. Compos. Part B Eng. 2013, 44, 231-241. [CrossRef]

30. Xu, L.; Huang, Y.; Zhao, C.; Ha, S.K. Progressive failure prediction of woven fabric composites using a multi-scale approach. Int. J. Damage Mech. 2016, 27, 97-119. [CrossRef]

31. Tran, T.; Kelly, D.; Prusty, B.G.; Pearce, G.; Gosse, J. A micromechanical sub-modelling technique for implementing Onset Theory. Compos. Struct. 2013, 103, 1-8. [CrossRef]

32. ASTM Standard D3171-15. Standard Test Methods for Constituent Content of Composite Materials; ASTM International: West Conshohocken, PA, USA, 2015. [CrossRef]

33. ASTM Standard D3039/D3039M-17. Standard Test Method for Tensile Properties of Polymer Matrix Composite Materials; ASTM International: West Conshohocken, PA, USA, 2017. [CrossRef] 